\title{
ARÍA MAGDALENA EN LOS ALBORES DEL CINEMATÓGRAFO: LA VIDA Y PASIÓN DE NUESTRO SEÑOR JESUCRISTO (FERDINAND ZECCA, 1902-1907) Y LA VIDA DE CRISTO (ALICE GUY, 1906)
}

\author{
ELENA MONZÓN PERTEJO \\ Investigadora independiente \\ elena.monzon@uv.es
}

\begin{abstract}
Resumen: Las primeras producciones cinematográficas de contenido bíblico han sido objeto de estudio en numerosos trabajos. Sin embargo, existe un vacío en lo referente al estudio de la presencia de María Magdalena en estas primeras producciones. El objetivo de este trabajo es estudiar estas primeras apariciones de la mujer de Magdala en el cine. En particular, son dos las películas en las que se pone fin al anonimato de este personaje: La Vida y Pasión de Nuestro Señor Jesucristo (Ferdinand Zecca, 1902-1907) y La Vida de Cristo (Alice Guy, 1906). Es por ello que ambas películas serán analizadas prestando especial atención al personaje objeto de estudio y a los referentes previos utilizados para construir al personaje, así como a las características específicas de las películas de este periodo. Al mismo tiempo, se plantea la existencia de posibles diferencias a causa de que la dirección de las producciones sea obra de un hombre y de una mujer.
\end{abstract}

Palabras clave: Cine silente / Cine bíblico / María Magdalena / Estudios de género.

MARY MAGDALENE AT THE DAWN OF CINEMA: THE LIFE AND PASSION OF JESUS CHRIST (FERDINAND ZECCA, 1902-1907) AND THE BIRTH, THE LIFE AND THE DEATH OF CHRIST (ALICE GUY, 1906)

Abstract: The first biblical movies have been a subject of research in several works. However, there is a lack in studying the presence of Mary Magdalene in the first cinematographic productions. The aim of this paper is to analyze these first appearances of the woman from Magdala in the movies. In particular, the end of Magdalene's anonymity begins with two productions: The Life and Passion of Jesus Christ (Ferdinand Zecca, 1902-1907) and The Birth, the Life and the Death of Christ (Alice Guy, 1906). Thus, these two films will be analyzed paying special attention to Mary Magdalene and its previous cultural references as well as the specific features of the movies in this period. In addition, issues related with the consequences derived from male and female authorship are discuss.

Key words: silent film / biblical film / Mary Magdalene / gender studies.

\section{Introducción}

El verano de 1897 es considerado como momento inaugural de la aparición del relato evangélico en el medio cinematográfico. En Francia, bajo la dirección de Léar (Albert Kirchner), se realizaba la película La pasión de Cristo. Con el apoyo de la organización católica La Bonne Presse, Léar rodó, al aire libre, una serie de tableaux vivants con los que se mostraban los momentos más importantes de la historia de Jesús. Desde entonces, son numerosas las producciones cinematográficas que han tratado esta temática. Es con la película de Martin Scorsese La última tentación de Cristo (1988) cuando el personaje de María Magdalena comienza a tomar cada vez mayor relieve en este tipo de obras, hasta convertirse en el personaje protago-

* Fecha de recepción: 15 de abril de 2018 / Fecha de aceptación: 21 de junio de 2018. 
nista de películas como la recién estrenada María Magdalena (Garth Davis, 2018). No obstante, aunque son diversas las publicaciones que estudian la presencia de temáticas bíblicas en las primeras décadas del cinematógrafo, ${ }^{1}$ son escasas las que se centran en la mujer de Magdala. ¿Cuándo aparece este personaje en el medio audiovisual? ¿Qué rostros de su multifacética figura emergen? ¿A partir de qué tradiciones y referentes es construida? Estas son algunas de las preguntas a las que se trata de dar respuesta en las siguientes páginas.

Para ello se analizan dos producciones francesas de la primera década del siglo XX: el film producido por la casa Pathé y dirigido por Ferdinand Zecca -La Vida y Pasión de Nuestro Señor Jesucristo (1902-1907)- y la obra dirigida por Alice Guy Blaché -La Vida de Cristo (1906)- de la compañía Gaumont. Entre los objetivos concretos de la presente investigación se encuentra la demostración de cómo en los inicios del nuevo medio fueron los referentes visuales, más que los literarios, los que sirvieron de guía para la creación de las producciones cinematográficas de contenido bíblico. En relación a ello, se mostrará cómo este aspecto afecta en un sentido concreto a la construcción de María Magdalena. Asimismo, se planteará la cuestión de si existen diferencias o no cuando la dirección de las películas está en manos de una mujer.

Metodológicamente, el estudio se plantea desde el ámbito de la iconografía y la iconología, siendo fundamental la fase del análisis iconográfico en el que se conjuga el tema detectado con las fuentes. Además del proceder propio de esta metodología y su adaptación al análisis del audiovisual, cuestión tratada previamente en otros trabajos, es la noción de continuidad y variación así como el recurso a la tradición cultural convencionalizada el utillaje metodológico que resulta más propicio para responder a los interrogantes planteados. ${ }^{2}$ Aby Warburg y Fritz Saxl legaron a la iconología la noción de continuidad y variación, por medio de la cual se hace referencia a los cambios y permanencias, letargos y renacimientos de las imágenes a lo largo del tiempo y las culturas. En íntima relación a ello se encuentra la tradición cultural convencionalizada, configurada por la historia de los tipos iconográficos, que ofrece un repertorio de recursos icónicos que sirve de guía y principio corrector para este tipo de estudios. ${ }^{3}$ Si bien el análisis previo de las producciones audiovisuales se ha realizado siguiendo un esquema que se puede consultar en las publicaciones indicadas, ${ }^{4}$ se ha optado por presentar el discurso final adaptándolo a una mayor facilidad de lectura que evitara repeticiones y agilizara la redacción.

Al adoptar la iconología como línea de pensamiento, se apuesta por el camino que se inicia partiendo de la propia imagen -imágenes audiovisuales en este caso- y no de premisas deterministas. Con esto último se rechazan aquellos planteamientos que parten del contexto para explicar la imagen, dado que dicho modo de proceder supone una actividad exegética y no un ejercicio hermenéutico. Así, el estudio se plantea desde una perspectiva eminentemente cultural, atendiendo a cuestiones formales y estilísticas como medio para llevar a cabo la aproximación al significado y no como finalidad. Por lo tanto, además del uso de dichas herramientas y planteamientos metodológicos para resolver los objetivos propuestos, se pretende estudiar, en concordancia con la perspectiva de la Historia Cultural, no sólo las obras analizadas sino también los ámbitos en las que estas son creadas y que, en una doble dirección, proyectan su influencia. Es por esto último que se hace posible la inclusión de cuestiones de género que presenta este trabajo.

\section{El problema de los materiales}

Las primeras décadas de la creación cinematográfica conllevan unas dificultades específicas del periodo en lo referente a los propios materiales. En primer lugar, la dificultad existente a la hora de realizar un listado exhaustivo de las producciones realizadas, debido a que muchas de ellas se han perdido y únicamente se conoce su título, fecha y, en el mejor de los casos, el nombre de los creadores. ${ }^{5}$ Junto a ello, hay que añadir la problemática

\footnotetext{
1 Véase por ejemplo: SHEPHERD, David J., 2013; BUCHANAN, Judith, 2007, pp. 47-60; COSANDEY, Roland; GAUDREAULT, André; GUNNING, Tom (eds.), 1992; GRACE, Pamela, 2009.

2 En relación a las posibilidades del método iconográfico-iconológico para el análisis audiovisual véase: MONZÓN, Elena, 2012 y MONZÓN, Elena, 2017.

${ }^{3}$ Respecto al término tradición cultural convencionalizada véase GARCÍA MAHÍQUES, 2009. Para la noción de continuidad y variación, obras de referencia principal son WARBURG, 2005 y SAXL, 1989.

${ }^{4}$ MONZÓN, Elena, 2012 y MONZÓN, Elena, 2017, pp. 36-40.

${ }^{5}$ Respecto a los títulos de las producciones, se ha optado por incluirlos en su traducción al castellano siempre que esta exista. No obstante, en muchas de las obras de este periodo, los títulos no fueron traducidos por lo que se han dejado en su idioma original.
} 
generada por las distintas versiones existentes de una misma película, cuestión esta que se produce fundamentalmente en las obras de los últimos años del siglo XIX e inicios del siglo XX. Igualmente, la datación de algunas de las cintas resulta también compleja, siendo necesario recurrir a estudios específicos de las filmotecas que albergan estos materiales. ${ }^{6}$

Dichas dificultades, tanto las referentes a la datación como a las distintas versiones, proceden, en parte, del modo en que la industria del cine se articuló en los primeros años. Eran los exhibidores de las cintas, y no los creadores, los que tenían la última palabra respecto al producto que habían comprado y, por tanto, en sus manos recaía el montaje final. Es por ello que a este tipo de cintas se les haya denominado como productos semi-finis. $^{7}$ Las posibles modificaciones a realizar sobre las cintas suponían un beneficio económico para los exhibidores de las mismas, ya que alterando el montaje obtenían distintos resultados que podían exhibir como nuevos. No obstante, este sistema de venta se vio disminuido en el año 1907 cuando la casa Pathé introdujo, paralelamente al sistema de venta, el sistema de alquiler. Ambas modalidades convivirían hasta 1910. Es con anterioridad a esta fecha cuando los problemas de datación y de versiones son más graves, dado que una vez instaurado el sistema de alquiler, el exhibidor ya no podía manipular las cintas. ${ }^{8}$

Estas cuestiones relacionadas con las dificultades de los materiales serán solventadas con el recurso no solo a la bibliografía específica del periodo sino también a lo recogido en los archivos de las compañías que produjeron los films. Esta cuestión es especialmente relevante para las dos obras seleccionadas para el análisis, ya que al estructurarse ambas como sucesiones de tableaux, resultaba fácil alterar el orden de dichas estampas sin modificar el argumento, cuestión esta que más adelante será tratada.

\section{El cine se apropia de la Historia Sagrada}

En los primeros años del cinematógrafo, la Biblia se convirtió, junto a obras literarias de autores clásicos como Shakespeare, en uno de los argumentos más utilizados en el nuevo medio. Este se valió de la larga tradición de representaciones previas de estos relatos en otros medios artísticos, como la literatura, la pintura, el teatro o los espectáculos de linterna mágica. La familiaridad de los relatos bíblicos para un público aún no acostumbrado a la narrativa audiovisual favorecía el interés de los cineastas y las productoras para elegir dichas narraciones. No obstante, el factor económico fue un elemento clave para que la Biblia adquiriera mayor presencia en el audiovisual. En concreto, es a partir de 1911 cuando se produce este auge como consecuencia de una sentencia emitida por la Corte Suprema de los Estados Unidos. El pleito tuvo su origen en la demanda que se interpuso contra la compañía Kalem por su uso de la novela de Lewis Wallace en su película BenHur (Sidney Olcott, 1907).

Como consecuencia de esta sentencia, dicha compañía quedó obligada a pagar derechos de autor al escritor, además de tener que destruir las copias del film. Con esta situación se daba inicio a la obligación del pago por derechos de autor en el mundo del cine. Por todo ello, en su afán de rentabilizar el dinero al máximo, la industria cinematográfica concentró gran parte de sus esfuerzos en la adaptación de los relatos evangélicos para sus producciones, dado que esta obra literaria carecía de derechos de autor. En este nuevo escenario, en el que se unían factores económicos y de familiaridad con los temas representados, los relatos bíblicos dotaban al nuevo medio no solo de estatus artístico sino también de fundamento moral. ${ }^{9}$ Así, en el periodo comprendido entre 1897 y 1927, el especialista en el cine silente de contenido bíblico David J. Shepherd contabiliza, entre Europa y América, al menos ciento veinte películas de esta temática, siendo con toda probabilidad muchas más las que se realizaron pero de las que no ha quedado constancia. ${ }^{10}$

La creación de Léar no era un elemento aislado en su tiempo, ya que simultáneamente en Alemania, concretamente en Horitz (Bohemia), se estaba filmando la representación de la pasión que tenía lugar en dicha localidad. Este proyecto corría a cargo

\footnotetext{
${ }^{6}$ En referencia a los problemas de datación de la obra de la casa Pathé consúltese: REDI, Riccardo, 1985, pp. 167-171 así como una síntesis de ello en BOILLAT, Alain y ROBERT, Valentine, pp. 32-55, en línea <http:// 1895.revues.org/3864> (Fecha de consulta 6-03-2018).

7 Respecto al concepto de producto semi-fini véase ELSAESSER, Thomas, 2006, pp. 67-86.

${ }^{8}$ ABEL, Richard, 1998, pp. 9-21.

9 BUCHANAN, Judith, 2007, pp. 49-51.

10 SHEPHERD, David J., 2013, p. 7.
} 
de los norteamericanos Marc Klaw y Abrahm Erlanger, quienes la estrenarían en Filadelfia también en 1897. ${ }^{11}$ Del mismo modo, Henry Vincent, en 1898, estrenaba en Nueva York su película The Passion Play of Oberammergau. ${ }^{12}$ También en 1898, Siegmund Lubin daba a conocer su obra Passion Play, rodada en el jardín de su casa con familiares y vecinos interpretando a los personajes. Lo más llamativo de la producción de Lubin era la representación de los milagros de Jesús haciendo uso de las posibilidades tecnológicas del nuevo medio.

De nuevo en el viejo continente, los hermanos Lumière, junto al director George Hatot, dedicaron parte de su trabajo a la vida de Jesús en el film La Vida y Pasión de Jesucristo (1898)..$^{13}$ En el año 1900 , en este caso en la península Itálica, se estrenaba, en la misma línea, la película de Luigi Topi y Ezio Cristofari titulada La Passione di Cristo (1900). Son estas tan solo algunas muestras de la presencia del relato bíblico en el cine de los primeros años. Sin embargo, en ellas el personaje de María Magdalena no cuenta con una definición y entidad clara, quedando en el anonimato. No es hasta que la casa Pathé produce su primera película sobre Jesús cuando la mujer de Magdala adquiere personalidad en la gran pantalla.

\section{El fin del anonimato: La Vida y Pasión de Nuestro Señor Jesucristo (Ferdinand Zecca, 1902-1907)}

Es con la firma Pathé, como se indicaba, con Ferdinand Zecca como director, cuando María Magdale- na aparece por primera vez en el relato cinematográfico. Existen diversas versiones de esta película ya que la propia casa Pathé fue ampliando el proyecto a consecuencia del éxito que tuvo la cinta. La primera versión, de dieciocho minutos de duración, fue rodada en 1902. En 1906, con el título La naissance, la vie et la mort du Christ, se amplió a treinta y siete minutos. La versión escogida para el análisis -con una duración de cuarenta y tres minutoses la última que se realizó y fue estrenada en 1907. Se trata de la cinta más extensa y la que mejor calidad tiene. No obstante, a diferencia del storyboard conservado en los archivos de Gaumont-Pathé, en la versión estudiada los intertítulos son más numerosos y están traducidos al inglés. Es por ello que dicha copia no es la realizada inicialmente, sino la utilizada para su distribución en el mercado norteamericano tras la instauración de una oficina de Pathé, en el año 1904, en Nueva York. ${ }^{14}$

A partir de treinta y cinco capítulos creados a modo de tableaux, se presenta la vida de Jesús desde su nacimiento hasta su ascensión a los cielos. Formalmente, toda la película, a excepción de tres de los capítulos, se elabora con cámara fija y planos generales. ${ }^{15} \mathrm{Al}$ igual que haría Lubin unos años antes, se emplea el trucaje para presentar las escenas de los milagros, siendo el truco por sustitución el más recurrente. Junto a ello, el uso del color colabora también en la creación de efectos, remarcando en ocasiones los elementos más importantes de la narración. En este sentido, se utiliza tanto la técnica del estarcido como la del entintado. ${ }^{16}$

\footnotetext{
${ }^{11}$ El objetivo del proyecto de Klaw y Erlanger consistía en filmar la tradición que existía en territorios germanos de representar la pasión. Dicha tradición se realizaba desde el siglo XIII, siendo pocas las localidades que la mantenían como consecuencia de la Reforma. SHEPHERD, David J., 2013, pp. 13-15.

12 No obstante el título de la cinta incita a pensar que el contenido refiere a la representación de la pasión que se lleva a cabo en la localidad bávara de Oberammergau, realmente el film fue rodado en la ciudad de Nueva York, utilizando la azotea de un edificio como espacio de rodaje. TATUM, W. Barnes, 2013, pp. 3-5.

${ }_{13}$ Shepherd indica que, aunque no se puede datar con total exactitud el inicio de la filmación de esta película, es probable que se comenzara en la primera parte del año 1898, ya que aparece en el catálogo de producciones de los Lumière dedicada a la segunda mitad del mismo año. SHEPHERD, David J., 2013, pp. 29-41.

${ }^{14}$ El storyboard puede consultarse en los archivos Gaumont Pathé <http://www.gaumontpathear chives. com/> (Fecha de consulta 09-02-2018). Respecto a las distintas versiones de la película así como a la internacionalización de la productora, véase: ABEL, Richard, 1998, p. 23 y SHEPHERD, David J., 2013, pp. 61-63.

${ }^{15}$ La sucesión de capítulos de la cinta visionada es el siguiente: 1. La Anunciación, 2. Llegada de José y María a Belén, 3. La estrella polar, 4. Siguiendo a la estrella, 5. La natividad y la adoración, 6. La matanza de los inocentes, 7. La huida a Egipto, 8. La Santa familia en Nazaret, 9. Jesús y los doctores, 10. Bautismo de Cristo, 11. Las Bodas de Caná, 12. María Magdalena a los pies de Jesús, 13. Jesús y la samaritana, 14. La resurrección de la hija de Jairo, 15. Cristo camina sobre las aguas, 16. La pesca milagrosa, 17. La resurrección de Lázaro, 18. La transfiguración, 19. Entrada en Jerusalén, 20. Jesús expulsando a los mercaderes del templo, 21. La última cena, 22. Jesús en el monte de los olivos. El beso de Judas, 23. Jesús ante Caifás, 24. Pedro niega a Cristo, 25. Jesús ante Pilatos, 26. La flagelación. La corona de clavos, 27. Jesús ante el pueblo, 28. Jesús cae bajo el peso de la cruz, 29. Calvario, 30. Cristo puesto en la cruz, 31. Agonía y muerte de Cristo, 32. Descenso de la cruz, 33. Jesús puesto en la tumba, 34. La resurrección y 35. La ascensión. Por otra parte, son los capítulos quinto, octavo y decimocuarto los que incluyen movimiento de cámara y el vigésimo sexto y vigésimo séptimo en los que se produce un cambio de plano general a planos medios.

${ }^{16}$ El truco por sustitución, truco de parada o paso de manivela «consiste en aprovechar la detención momentánea de la filmación para modificar algún elemento del campo visual encuadrado por la cámara antes de continuar dicha filmación, de
} 
Es el capítulo decimosegundo, titulado "María Magdalena a los pies de Jesús", el que presenta al personaje objeto de estudio. Se trata de la escena en la que María Magdalena, arrodillándose a los pies de Jesús, recibe el perdón de sus pecados (fig. 1). Así, su inclusión en el relato se hace siguiendo la tradición de la Magdalena mítica, aquella creada por los Padres de la Iglesia latina a partir de la mezcla de personajes. ${ }^{17}$ Este personaje no vuelve a aparecer hasta el capítulo titulado "Calvario", donde la mujer, al tiempo que llora, se aproxima a Jesús con los brazos extendidos con gestos de dolor, seguida por la Virgen que se apoya en Juan. Durante la crucifixión, la Magdalena continúa con sus gestos de sufrimiento arrodillándose a los pies del madero. Su largo cabello le cubre la espalda en el momento de la agonía y muerte de Jesús. Tras ello, un relámpago que transforma la situación lumínica de la escena, pone fin a la agonía del crucificado, dejando a la mujer de Magdala y a la Virgen arrodilladas a los pies de la cruz. La escena termina con todos los personajes siguiendo el cuerpo del fallecido, siendo María Magdalena el último personaje en salir del plano y cerrándose así el capítulo.

Las escenas de la resurrección, con una luminosidad más cálida gracias a la presencia del color amarillo, incluyen el truco por sustitución para provocar el surgimiento de Jesús de la tumba. En dichas escenas están presentes María Magdalena, la Virgen y Juan, quienes reciben del ángel la noticia de la resurrección. El último capítulo corresponde a la ascensión del resucitado a los cielos ante sus seguidores y seguidoras que se arrodillan orantes. Durante la resurrección, elemento clave dentro de la fe cristiana, la Magdalena no ostenta ningún protagonismo, siendo un personaje más dentro del grupo de testigos. En este sentido, se ha optado por otorgar mayor importancia a la propia acción de la resurrección que conlleva el despliegue de los efectos especiales que permiten la visualización de la misma. Estos pasajes, si se atiende a lo dicho en los evangelios, no siguen literalmente ninguno de ellos. En relación a ello, uno de los elementos más llamativos es la presencia de la madre de Jesús, ba-

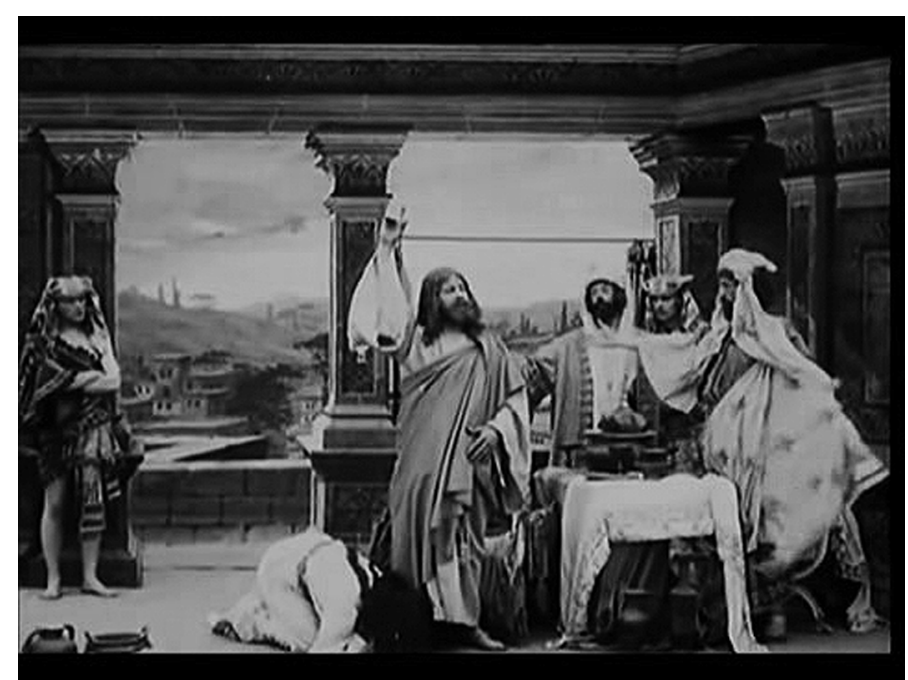

Fig. 1. Ferdinand Zecca, "María Magdalena a los pies de Jesús", La Vida y Pasión de 1902-1907.

sada en tradiciones no canónicas como las que recoge Santiago de la Vorágine:

\begin{abstract}
Aseguran algunos relatos que el mismo día de la resurrección Cristo se apareció también separadamente a Santiago Alfeo, a José de Arimatea y a la Virgen María. De ninguna de estas tres apariciones hablan los textos sagrados, pero sí vamos a hablar nosotros. (...) En cuanto a la tercera de estas apariciones, aunque los evangelistas nada digan de ella, se cree comúnmente que el Señor, antes que a nadie, se apareció a la Virgen María. Que la Iglesia aprueba esta creencia parece inferirse del hecho de que la estación litúrgica del día de Pascua se celebre en la basílica de Santa María la Mayor. Si alguien dijere que esta aparición no debe tenerse por verdadera, puesto que los evangelistas no la mencionan, deberían decir también que Cristo resucitado no volvió a ver más en la tierra a su Madre, porque tampoco los evangelistas hablan para nada de que Cristo viera a su Madre desde que expiró en el Calvario hasta su ascensión a los cielos. Ahora bien, la sola idea de que semejante Hijo se hubiera conducido tan desatentamente y con tanto despego con semejante Madre repugna a cualquier conciencia. ${ }^{18}$
\end{abstract}

modo que el cambio entre la toma previa a la parada y la toma siguiente se produzca de forma brusca y sin solución de continuidad», CUÉLLAR ALEJANDRO, Carlos A., 2004, p. 103. Por otra parte, el proceso de coloración por estarcido es un proceso mecánico que consiste en recortar algunas zonas del fotograma que luego son utilizadas como plantillas que, al superponerlas sobre la película final, provocan que tan sólo las zonas que habían recibido la coloración sean visibles. Por otra parte, el entintado de los fotogramas se realizaba dando baños de color a las distintas secciones de la cinta. MOLINA-SILES, Pedro; PIQUER-CASES, Juan C.; CORTINA MARUENDA, Francisco J., 2013, p. 529, en línea <https://riunet.upv.es/bitstream/handle/10251/30118/61. pdf?sequence=1\&isAllowed=y> (fecha consulta 12-02-2018). Respecto a las técnicas del color en los primeros años del cine véase también READ, Paul, 2009, pp. 9-46.

17 Respecto a la configuración de la Magdalena mítica véase: MONZÓN PERTEJO, Elena, 2011, pp. 529-531.

18 VORÁGINE, Santiago, 2001, pp. 232-233. 


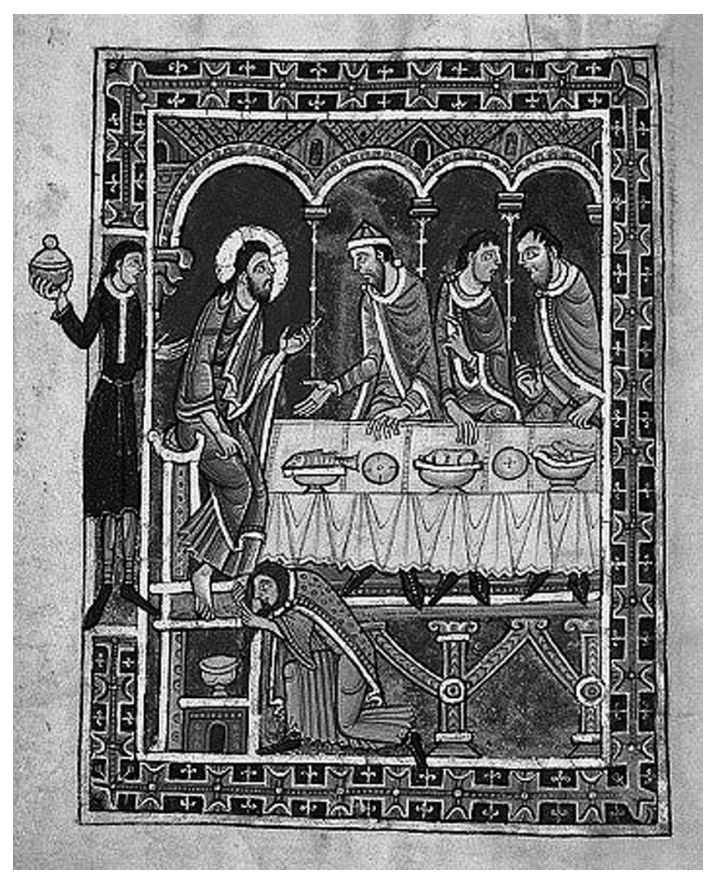

Fig. 2. "Cristo en casa de Simón el fariseo", Salterio de Saint Albans, p. 36, siglo XII.

Seguidamente, Vorágine explica que los evangelistas omitieron el hecho de que Jesús se presentara primero ante su madre para evitar que ello se entendiera como "delirios calenturientos de una madre" debido a las "alucinaciones procedentes del intenso amor que tenía a su Hijo". Asimismo, Vorágine señala que las apariciones del resucitado ante su madre "naturalmente se daban por supuestas". ${ }^{19}$

Centrando la atención de nuevo en María Magdalena, se aprecia como es la tradición del personaje y no la fidelidad a las fuentes neotestamentarias la que domina la construcción del relato en relación a este personaje. El elemento central es el recurso a esa Magdalena mítica que se indicaba, oficializada desde los siglos medievales. Respecto a la presentación de María Magdalena en la película, no se indica el lugar en el que acontece, por lo que pueden ser diversas las localizaciones en función de los personajes que forman parte del híbrido de la Magdalena mítica. Así, se produce una problemática a la hora de localizar la fuente de dicha escena. No obstante, con el recurso a dos elementos se puede aclarar dicha situación. El primero de ellos refiere a que la unción se realiza en los pies y no en la cabeza de Jesús, por lo que quedarían descartadas las narraciones de Mateo $(26,6-12)$ y de Marcos (14,3-9). Por lo tanto, únicamente restarían como posibles los relatos de la pecadora de Lucas $(7,36-38)$ y de la narración joánica $(12,1-8)$. Es en este punto donde la tradición cultural convencionalizada aporta luz para solventar esta problemática.

Son varios los libros devocionales en los que se representa la escena de la unción de la pecadora a los pies de Jesús. Entre ellos se encuentran el Salterio de Saint Albans, el Evangelario de Enrique el León y The Vaux Passional. En los dos primeros se presenta dicha escena sin aludir, en el título, al nombre de María Magdalena. El primero titula la unción como "Cristo en casa del fariseo", pudiéndose así adjudicar la referencia bíblica de Lucas 7,36-50 (fig. 2). La denominación dada al segundo remite a la misma fuente: "La pecadora de Lucas en casa de Simón el fariseo". Aunque, como se indicaba, no aparece el nombre de la mujer de Magdala, se puede deducir que es ella la que está siendo representada, tanto por el contexto exegético del momento como por el resto de representaciones que siguen a la escena de la unción. Éstas quedan dedicadas a la entrada en Jerusalén y, por tanto, dan inicio al ciclo de la Pasión y Resurrección, momentos en los que este personaje adquiere protagonismo. A ello hay que añadir que en el caso de las imágenes contenidas en The Vaux Passional (Peniarth MS 482D), datado de finales siglo $X V$, sí que ha sido incluido el nombre de la mujer en el título: "María Magdalena ungiendo los pies de Jesús" (f.15v).

Respecto a las escenas de la crucifixión en la película, María Magdalena es presentada como una figura doliente de exacerbado dolor, en contraste con la contención de la Virgen, siguiendo de este modo otra tradición del personaje. Un claro ejemplo de ello es la obra Crucifixión, realizada por Masaccio en 1426 (Museo di Campodimonte, Nápoles), donde la Magdalena, a los pies de la cruz, muestra su espalda cubierta con sus largos cabellos -al igual que en el film- mientras expresa con los brazos su gran sufrimiento. Esta exacerbada actitud de la figura llorona contrasta con el recogimiento de la madre del crucificado, de nuevo al igual que sucede en la obra de Zecca. A partir del siglo XII, con el incremento del interés por la pa-

19 VORÁGINE, Santiago, 2001, pp. 232-233. 
sión de Jesús, reforzado por la literatura piadosa, María Magdalena se convirtió en uno de los personajes principales de este episodio. A este respecto, Pseudo Buenaventura trató la cuestión del sufrimiento de la Virgen durante la crucifixión de su hijo, señalando que esta sí que lloró y desfalleció en el momento que la lanza atravesó el costado de Jesús. ${ }^{20}$ La asistencia de Juan a la madre del crucificado se aprecia, por ejemplo, en la Crucifixión de Giotto (Crucifixión, 1302-1305, Cappella degli Scrovegni, Padua) así como en la obra de Matías Grünewald (Crucifixión, tabla central del Retablo de Isemheim, 1512-1516, Musée d'Unterlinden, Colmar). Estas mismas actitudes y maneras de sufrir de los tres personajes -María Magdalena, la Virgen y Juan- son las representadas en el film de la casa Pathé.

En las escenas de la resurrección, la importancia de María Magdalena se ha disminuido en comparación con lo señalado en los evangelios así como en parte de su tradición. De hecho, la primera imagen conocida de este personaje la muestra en la mañana de resurrección asistiendo al sepulcro -decoración de la sala bautismal de una vivienda de Dura Europos, datada en el siglo III-. Este tipo de imágenes continuaron en el tiempo, siendo numerosos los ejemplos a lo largo de distintas épocas, soportes y estilos. Tómese como ejemplos una placa procedente de una caja de marfil conservada en el British Museum de Londres, realizada en las dos primeras décadas del siglo $\mathrm{V}$, así como la representación de dicha escena en el previamente mencionado Salterio de Saint Albans o en obras más tardías como las de Duccio di Duccio di Buonsegna (Las santas mujeres en el sepulcro, 1308-1311, Museo dell'Opera del Duomo, Siena) o en la de Benjamin West de 1805 (Las mujeres en el sepulcro, 1805, Brooklyn Museum, Nueva York).

No obstante, aunque todos los ejemplos señalados forman parte de la tradición de este personaje $y$, por tanto, tienen sus ecos en el film, a la hora de tratar las películas de estos primeros años resulta imprescindible la referencia a las Biblias ilustradas del Ochocientos. Concretamente, son tres las obras que mayor influencia directa tuvieron en las primeras representaciones de las narraciones evangélicas en el cine: la Santa Biblia de Gustave
Doré (1866), Los Santos Evangelios de Alexandre Bida (1873) y La vida de Nuestro Señor Jesucristo de James Tissot (1896-1897). Para el caso concreto de la película de la casa Pathé, son varios los especialistas que señalan que se utilizó, de manera directa, la obra de Doré para la creación de las imágenes cinematográficas. ${ }^{21}$ El recurso a las manifestaciones artísticas previas al cinematógrafo formó parte del discurso de legitimación del cine en sus primeros años, momento en que era considerado, despectivamente por muchos, como un entretenimiento popular sin valor artístico.

A través de la combinación de realismo y teatralidad, Doré generó en sus ilustraciones bíblicas toda una serie de espacios escénicos configurados a modo de tableaux que sirven de base a la película dirigida por Zecca. En la Biblia de Doré, María es concebida en su confusión con la pecadora de Lucas. No obstante, no se le representa en el momento de la unción sino en sus años de penitencia en el desierto, añadiéndose de este modo su vida legendaria en la ilustración. Más adelante, en las escenas de la crucifixión, en concreto la que lleva por título "La crucifixión" relativa al pasaje de Lucas 23,34, Doré muestra, al igual que el film, los rayos de luz que caen sobre el crucificado. Este artista, para representar la resurrección, siguió el relato de Mateo 28,5-6, creando una escenografía que es imitada en la película: el acceso al sepulcro se realiza a través de un descenso tras el cual se produce el encuentro con el ángel (fig. 3). Bida y Tissot, al igual que Doré, presentan a la mujer también en su vertiente mítica. Ambos la muestran en el momento de la unción, pero Tissot añade además la confusión con María de Betania.

Como se indicaba al principio, el film de Zecca está articulado por medio de una serie de tableaux. Esta característica es un elemento fundamental en los inicios del cine, suponiendo un campo de experimentación para la nueva tecnología. El recurso a obras pictóricas precedentes era de tanta importancia que en los catálogos de la firma, en concreto en lo referente a la versión de 1902, se señalan las obras empleadas para elaborar cada uno de los capítulos de la película. De hecho, las representaciones previas eran consideradas no como interpretaciones personales de un artista en

\footnotetext{
20 HASKINS, Susan, 1996, pp. 219-230 y 479 (notas 27 y 28).

${ }^{21}$ Véase SHEPHERD, David J., 2013, p. 44 y BOILLAT, Alain y ROBERT, Valentine, 2010, pp. 32-55. La relación entre el trabajo de Gustave Doré y el cine ha sido ampliamente estudiado por Valentine Robert en otras publicaciones además de la señalada: ROBERT, Valentine, 2014, pp. 287-295. Robert indica que el uso de las representaciones de Doré en el cine se debe, en gran medida, a que sus ilustraciones presentaban una mise en scêne propia del medio cinematográfico así como la existente tradición de proyectar sus obras en linterna mágica.
} 


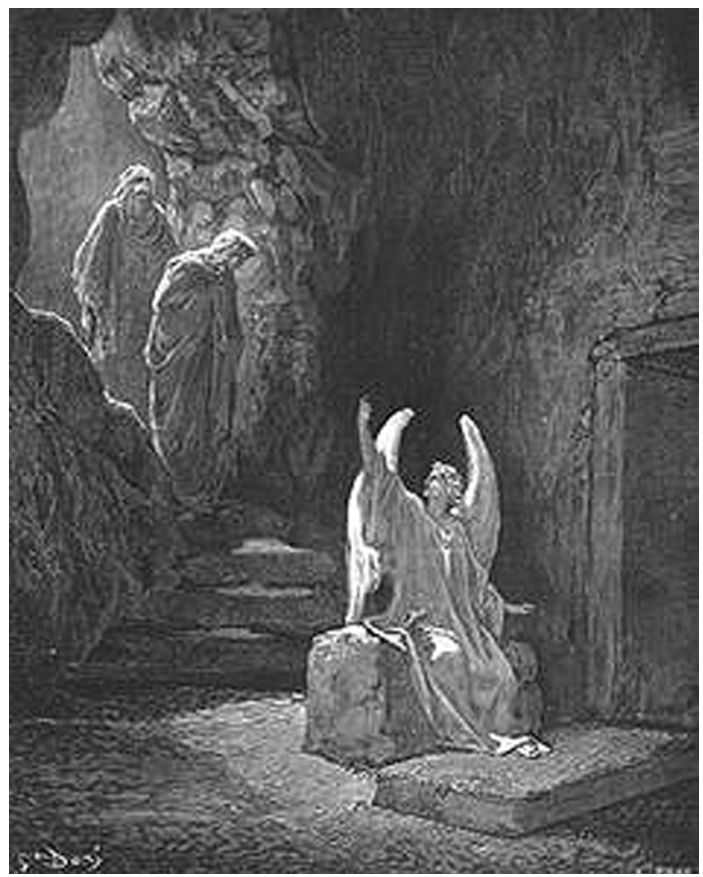

Fig. 3. Gustave Doré, “La Resurrección”, Sainte Bible, 1866.

un contexto determinado, sino como auténticos documentos que dotarían a la película de fidelidad y veracidad. ${ }^{22}$ Junto a ello, la vasta tradición de representaciones bíblicas había generado todo un repertorio de imágenes y formulaciones ya establecidas que, como se ha señalado previamente, facilitaban la comprensión de los argumentos por parte del público.

La importancia del uso de obras pictóricas era tal que la casa Pathé contaba con personal especializado en este tema. En concreto, para los films de contenido bíblico, Vincent Lorant-Heilbron era el encargado en dichas cuestiones. El film objeto de análisis es uno entre los muchos títulos de esta firma que centraban la atención en temáticas reli- giosas -Samsom et Dalila (Ferdinand Zecca, 1902), La Vie de Moïse (Lucien Nonguet, 1905), Joseph vendu par ses frères (Paul Gavault y Georges Berr, 1909) y Le Judgement de Salomon (Henri Andréani, 1912)- en su afán por convertirse en referente de este género que, por otra parte, otorgaba la posibilidad de ampliar el mercado debido a la vertiente educativa y moral del contenido de los films. ${ }^{23}$ Por lo tanto, estas cuestiones demuestran que son los recursos visuales procedentes de la tradición cultural los que tienen mayor peso a la hora de crear las producciones fílmicas y no las fuentes literarias.

¿Cómo afecta todo ello, o cómo se aprecia esta situación, en relación al personaje de Magdala? Este personaje es presentado en su vertiente mítica, resultado de las confusiones patrísticas con otros personajes del Nuevo Testamento. Así, María Magdalena abandona el anonimato precedente en el cine para aparecer articulada como la pecadora arrepentida. ${ }^{24}$ De este modo, se mantiene el constructo patrístico a raíz de su continuidad en la tradición cultural, que no hace sino afianzar y enfatizar esta vertiente de la mujer de Magdala. Por lo tanto, y debido a la importancia dada a las representaciones artísticas entendidas como auténticos documentos, es el mito de la Magdalena el que es introducido en el celuloide en el momento en que María Magdalena hace su primera aparición dado que, junto a las experimentaciones técnicas y la obtención de beneficios económicos, es la misericordia de Jesús y su capacidad de realizar milagros el principal interés de los creadores del film. Por tanto, se vuelve a reforzar la idea de que es el repertorio de recursos visuales previos al cinematógrafo -especialmente las decimonónicas Biblias ilustradas- las que ostentan mayor influencia en esta creación.

\section{María Magdalena en La vida de Cristo de Alice Guy Blaché (1906)}

Con varios títulos alternativos, pero conocida principalmente como La vida de Cristo, en la Francia de 1906 se estrenaba este film dirigido por la cineasta Alice Guy. ${ }^{25}$ De nuevo, al igual que la

\footnotetext{
22 ROBERT, Valentine, 2014, pp. 263-281 y ROBERT, Valentine, otoño 2013, p. 20.

23 SHEPHERD, David J., 2013, pp. 42-44.

${ }^{24}$ Se podría argumentar en este punto que la revelación de las confusiones patrísticas es una cuestión propia del siglo XXI desconocida en los inicios del siglo precedente. No obstante, aunque si bien es cierto que es a partir del desarrollo de la teología feminista en el último cuarto del siglo XX cuando este tema adquiere verdadera relevancia, existen precedentes al respecto. De hecho, ya en 1519, Jacques Lefèvre D'Étaples destapaba la construcción patrística de María Magdalena: LEFĖVRE D'ÉTAPLES, Jacques, 1519, en línea <https://books.google. es/books?id=LDc8AAAACAAJ\&printsec=frontcover\&hl=es\&source= gbs_ge _summary_r\&cad=0\#v=onepage\&q\&f=false> (fecha consulta 9-04-18). La obra de Lefèvre d'Étaples fue censurada e incluida en el Index, pero otros autores se hicieron eco de lo dicho en su texto. Al respecto véase MYCOFF, David (trad.), 1989.

25 Otros de los títulos alternativos fueron La Passion y La Naissance, la Vie et la Mort du Christ.
} 
obra de Zecca, y que gran parte de las películas del momento, la cinta de Guy se articula mediante una sucesión de tableaux con los que se escenifica la vida de Jesús. El visionado del film, y la consulta respecto al mismo en los archivos Gaumont, informan sobre el número de tableaux que componen la cinta: veinticuatro en total, con una duración de treinta y tres minutos y treinta segundos. A diferencia de la película de Zecca, no se ha empleado el uso del color en ninguna de sus técnicas y los intertítulos aparecen en francés. En lo referente a María Magdalena vuelven a ser, al igual que en el film de la casa Pathé, tres los episodios fundamentales: el quinto tableaux titulado "Marie-Magdeleine lave les pieds de Jésus", el vigésimo primero bajo el nombre "L'agonie" $y$, por último, el que da fin a la película y corresponde a "La résurrection".

La presentación de la mujer de la Magdala se realiza del mismo modo que en la película de Zecca, en un interior doméstico con diversos personajes donde esta obtiene el perdón de Jesús tras ungir sus pies. En las escenas de la crucifixión destaca especialmente el capítulo de "La agonía". Esta escena, que comienza como un tableaux estático que es interrumpido por la llegada de los romanos para clavar la lanza en el costado del crucificado, María Magdalena y la madre de Jesús comparten el protagonismo. En contraste con el film de Zecca, la expresión de dolor de ambas mujeres es equivalente, mostrando un sufrimiento contenido sin grandes gestos de consternación. En "La resurrección", representada al igual que en la película de Pathé por medio del trucaje, son numerosos los ángeles que asisten a la aparición del resucitado. Una vez este ha desaparecido, un grupo de mujeres accede a la cueva donde se encuentra el sepulcro, y arrodilladas ante la tumba vacía en actitud orante se pone fin a la película. De esta última escena llama la atención que María Magdalena, que era la que lideraba el grupo de mujeres, desaparezca tras recibir la noticia del ángel y no esté presente en la oración ante el sepulcro vacío.

Dicho esto, resultan evidentes los numerosos paralelismos en la construcción de este personaje en las películas de las dos compañías cinematográficas en competencia en ese momento en Francia, la casa Pathé y la firma Gaumont. Si en el caso de la primera se tiene constancia de que fueron las ilustraciones de Gustave Doré las empleadas como documentos, para el film de Gaumont fue la Bi- blia de Tissot la que se tomó como referente. La cineasta no sólo admiraba la obra de este artista, sino que consideraba sus ilustraciones como un excelente material debido a que fueron realizadas durante el viaje del artista a Tierra Santa. Es por ello que para Alice Guy las imágenes de Tissot eran auténticos documentos que, por estar realizados en las localizaciones originales, veían incrementada su fidelidad. ${ }^{26}$ La importancia de las ilustraciones de Tissot se aprecia en numerosos elementos, como es el caso del vestuario que lleva la actriz que interpreta a María Magdalena y que coincide con el de la ilustración bíblica (fig. 4).

La propia Alice Guy, en sus memorias, explica la importancia de estas ilustraciones:

I had long wanted to make a film about the fine drama of the Passion. At the 1900 Exposition, Tissot had published a very beautiful Bible illustrated after the sketches he had made in the Holy Land. It was ideal documentation, for decor, costumes and even local customs. I bought that Bible, which I still have. ${ }^{27}$

Por lo tanto, ambas producciones comparten no sólo su confianza en las Biblias ilustradas como fuentes sino también la construcción que se realiza de María Magdalena. No obstante, el hecho de que el film de la casa Pathé esté dirigido por un hombre y el de la firma Gaumont por una mujer, ha sido objeto de estudio en distintas publicaciones. ¿Se pueden encontrar diferencias entre ambas películas que tengan como causa el hecho de la diferencia de género en su autoría? ¿O, por el contrario, ambas producciones responden, independientemente de sus creadores, a los estándares narrativos del momento? En las próximas líneas se explicará cómo ambas cuestiones no son excluyentes sino que, por el contrario, conviven.

Respecto a la primera cuestión, hay autores que señalan la existencia de diferencias a causa de cuestiones de género. Tanto Alison McMahan como Richard Abel son partidarios de esta opinión, subrayando que, por ello, el film de Guy cuenta con peculiaridades que la distinguen de otras producciones del momento. Concretamente, McMahan y Abel apuntan la importancia de que sean mujeres las protagonistas de los milagros elegidos para la película de Guy, entre ellos el de la conversión de María Magdalena. Junto a ello, evidencian la cuestión de que son numerosas las actrices que aparecen en el film, tanto niñas interpretando a los ángeles como los considerables grupos de mu-

26 MCMAHAN, Alison, 2002, pp. 102-103.

27 SLIDE, Anthony (ed.), 1996, p. 45. 


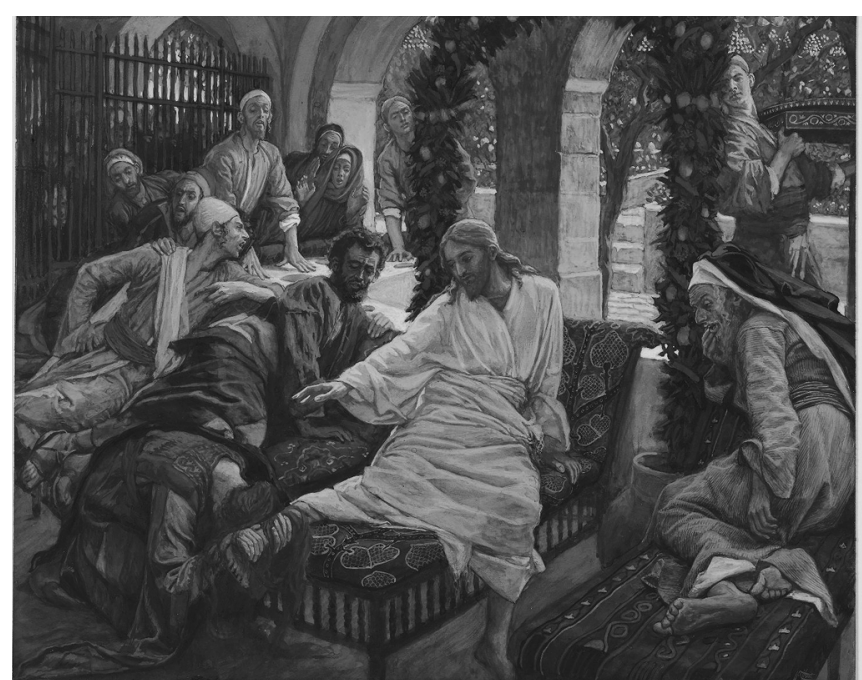

Fig. 4. James Tissot, "El perfume de Magdalena", La vida de Nuestro Señor Jesucristo, Brooklyn Museum, Nueva York, 1886-1894.

jeres en escenas como la de la crucifixión o la resurrección previamente comentadas. ${ }^{28}$

Otras autoras van más allá al considerar que la obra de Guy es una versión feminista de la vida de Jesús. Este es el caso de Gwendolyn Audrey Foster, quien no solo incide constantemente en el gran número de mujeres y niñas que aparecen como testigos de la vida de Jesús, sino que afirma que "Christ himself is feminized and eroticized". Foster indica que Guy crea una obra en la que destaca la perfecta fusión entre lo teatral y lo realista, predominando la naturalidad y la humanidad en una visión feminista de la historia. Dicha humanidad emana de los personajes y, señala Foster, la humanidad "is not defined here a white male". Desde el punto de vista de esta autora, la película está presentada desde la perspectiva de las niñas que actúan como ángeles sujetando los títulos de cada capítulo (fig. 5), a lo que se añade que se trata de una obra "that is performed and enacted by women and children throughout the entire narrative". Este gran número de mujeres conducien- do la narración y llenando los espacios de humanidad con su presencia, participación y papel de testigos activos de los acontecimientos, dan lugar a una feminización de la vida de Jesús. ${ }^{29}$

Alice Guy, como pionera del cine en un mundo dominado, en sus esferas superiores, por varones blancos, tuvo que hacer frente a un mayor número de obstáculos que sus compañeros. La propia Guy, en sus memorias, explica cómo frecuentemente se le preguntaba el porqué de haber elegido una profesión no acorde a las de su sexo:

I have often been asked why I chose so unfeminine a career. Yet, I have not chosen this career. No doubt my destiny was traced before my birth and I have merely followed a Will whose name I do not know. Strange fate $!^{30}$

A pesar del éxito de esta pionera del cine, y de la gran producción de obras que generó, su nombre, a diferencia del de directores o asistentes de dirección de su época, ha quedado oculto en la historia del cine hasta la década de 1990, momento en el que su figura comienza a ser recuperada. Cuestiones relacionadas con la dirección cinematográfica y el hecho de ser mujer, fueron una constante en la vida de Alice Guy quien en 1914, con artículo titulado "Woman's Place in Photoplay Production" (fig. 6), declaraba:

There is nothing connected with the staging of a motion picture that a woman cannot do as easily as a man, and there is no reason why she cannot master every technicality of the art. The technique of the drama has been mastered by so many women that it is considered as much her field as a man's and its adaptation to picture work in no way removes it from the sphere. The technique of motion-picture photography, like the technique of the drama, is fitted to a woman's activities. ${ }^{31}$

Junto a las numerosas temáticas que Guy trató en sus películas, hay una cinta en la que, haciendo uso del dispositivo de intercambio de roles atribuidos a hombres y mujeres, la cineasta plantea cuestiones como el acoso callejero o la desigualdad en las tareas del hogar. Se trata de la comedia Les Résultats du féminisme, estrenada en 1906 con una duración de siete minutos.

Por otra parte, y en relación a la segunda cuestión planteada líneas atrás, ambas producciones com-

\footnotetext{
28 MCMAHAN, Alison, 2002, pp. 102-103 y ABEL, Richard, 1998, pp. 164-166.

29 FOSTER, Gwendolyn Audrey, 2013, en línea <http://filmint.nu/?p=9219> (fecha de consulta 11/04/2018).

30 SLIDE, Anthony (ed.), 1996, p. 1.

${ }_{31}$ BLACHE, Alice, 1914, p. 195, en línea <https://archive.org/stream/movingpicturewor21newy\#page/ 194/mode/2up> (fecha de consulta 11-03-2018).
} 
parten, como se ha mostrado, la articulación de la narrativa por medio de distintos tableaux. Es este un tema que ha sido ampliamente estudiado en el ámbito de la historia del cine desde hace décadas y que ha sido objeto de debate. Richard Abel señala que el uso del efecto tableaux es un rasgo definitorio del cine creado en Francia en la fase que se denomina como cine de atracciones. ${ }^{32}$ Fue Tom Gunning quien acuñó dicho término con el objetivo de hacer referencia a las creaciones fílmicas previas al año 1908. Tom Gunning empleó este término en la década de 1980 como resultado de la renovación historiográfica iniciada a finales de la década previa. Gunning estaba haciendo una crítica a la consideración del cine de los primeros tiempos como cine imperfecto o estadio preparatorio del cine posterior entendido dentro de una lógica que adjudicaba a la historia del cine una evolución lineal, planteamiento rechazado por este autor. ${ }^{33}$

El cine de atracciones quedaba caracterizado por el interés de las cintas no tanto en el desarrollo argumental sino en las posibilidades tecnológicas del cinematógrafo para "presentar series de vistas a una audiencia fascinada por su poder ilusorio". ${ }^{34}$ El cine de atracciones vería disminuida su presencia cuando la narrativización, especialmente a partir de las obras de D.W. Griffith, se asentara como modelo normativo. Sin embargo, ambas modalidades cinematográficas no son excluyentes, sino que coexistieron en el tiempo aunque el peso de una y otra variase en cada momento. ${ }^{35} \mathrm{El}$ cine de atracciones, lejos de ser un marco bien delimitado que englobe a producciones homogéneas, incluye dentro de sí películas tan diversas como Salida de los obreros de la fábrica (Hermanos Lumière, 1895) y Ejecución de un elefante (Thomas Edison, 1903), a otras como las de Zecca o Guy. Así, mientras en las dos primeras es el efecto mostrativo el predominante, en las obras de Zecca y Guy existe una mayor narrativización que no renuncia a la espectacularidad de los trucajes. Es por ello que André Gaudreault concibió una primera fase de este tipo de cine a la que llamaría cine mostrativo de atracciones y que englobaría, de manera general, desde las primeras producciones hasta el año 1908. Una segunda fase, denominada por Gaudreault como sistema de integración na-

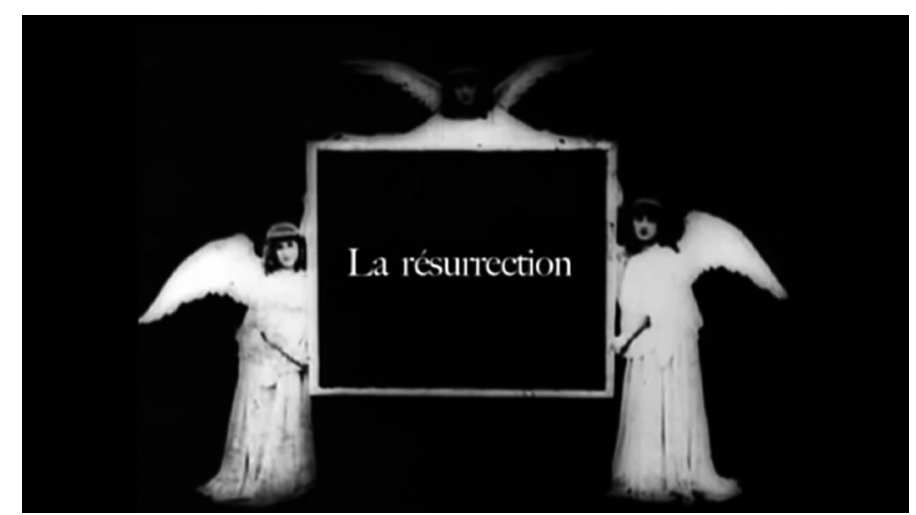

Fig. 5. Alice Guy Blaché, intertítulo del capítulo "La Resurrección”, La vida de Jesús, 1906.

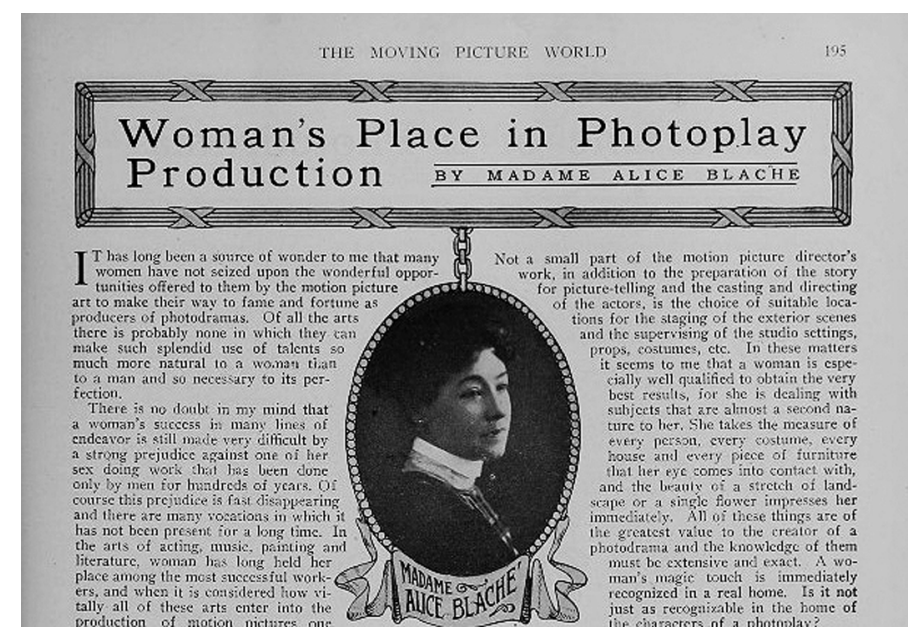

Fig. 6. Recorte de prensa del artículo de Alice Guy Blaché "Woman's Place in Photoplay Production", The Moving Picture World, 1914.

rrativa, incluiría a las cintas creadas desde ese año hasta la fecha de $1914 .^{36}$ Es en esta segunda fase en donde hay que incluir las películas analizadas en el presente trabajo, aunque sus fechas sean anteriores a las delimitaciones cronológicas realizadas por Gaudreault.

\footnotetext{
32 ABEL, Richard, 1996, p. 113.

33 Véase respecto al término "cine de atracciones": GUNNING, Tom, 1986, pp. 63-70. Sobre la renovación historiográfica: GUNNING, Tom, 2004, pp. 41-50 y GAUDREAULT, André, 2007, pp. 10-28

${ }^{34}$ GUNNING, Tom, 1986, p. 64.

35 Véase GUNNING, Tom, 2004, pp. 41-50 y GUNNING, Tom, 1986, pp. 63-70.

36 GAUDREAULT, André, 2007, p. 26.
} 
Ferdinand Zecca y Alice Guy utilizan el efecto tableaux para sus creaciones, así como el uso de los efectos especiales, más notorio en la obra del primero quien además hace uso de distintas técnicas del color. ${ }^{37}$ Por lo tanto, el deseo mostrativo aparece en estas cintas $y$, sin embargo, existe una narración con episodios derivados de los principios de causalidad argumental. No obstante, el deseo de contar una historia se hace más evidente en la cinta de Guy, quien en varios de sus escritos insistía con frecuencia en la importancia de narrar una historia y trasmitir emociones. ${ }^{38}$ No hay que olvidar que el hecho de presentar la vida de Jesús como estampas o cuadros (tableaux), conecta perfectamente con el modo en que la historia bíblica había sido narrada desde siglos atrás. En este sentido, Vicente J. Benet afirma que "las imágenes que escenifican algunos de sus momentos culminantes son perfectamente comprensibles porque forman parte de referentes culturales que todo el mundo conoce (...). No necesitan grandes justificaciones narrativas para trasladarse a imágenes fácilmente reconocibles por el público del momento".39

\section{Conclusiones}

Si bien son claras las similitudes entre ambas películas en su uso de los tableaux como elemento vertebrador de la narración así como la inclusión de las posibilidades no sólo narrativas sino también efectistas de la nueva maquinaria, las posibles diferencias resultantes del género de los creadores son más sutiles. No obstante, existe cierto acuerdo que la presencia de mujeres en la obra de Alice Guy es mayor, siendo la intensidad y el significado de ello lo que queda oscilante y abierto al debate de si supone una visión "feminista" de la historia de Jesús o no. Independientemente de ello, es en este tipo de producciones en las que se ofrece al público la vida de Jesús a través de imágenes en movimiento -motion pictures- $y$ así también la imagen de María Magdalena. Pathé y Gaumont, las compañías que produjeron los films de Zecca y Guy respectivamente, competían por el mercado del cine en la Francia de la primera década del siglo XX. Así, dos producciones francesas, de fechas similares, con similares dispositivos narrativos, misma temática y recurso a las Biblias ilustradas del siglo precedente como documentos para aportar fidelidad, hacen emerger a
María Magdalena con nombre propio en el audiovisual.

La mujer de Magdala, como se ha tratado de demostrar a lo largo de estas páginas, es presentada en su habitual confusión con la pecadora de la narración lucana, presente en la crucifixión y en la resurrección, aunque sin el protagonismo que las fuentes neotestamentarias le otorgan en dichos episodios. Por lo tanto, el nuevo medio de comunicación no incluye novedades en la construcción de este personaje, sino que el mito de María Magdalena, oficializado en el siglo VI por Gregorio Magno, continúa en las primeras producciones cinematográficas. En consecuencia, el primer cine de contenidos bíblicos, articulado como estampas piadosas influenciadas por Doré y Tissot, mantienen el misógino constructo de la pecadora arrepentida que no hace sino evidenciar la capacidad de Jesús para obrar milagros.

De este modo, se demuestra también lo adelantado al principio del trabajo: cómo la tradición visual de este personaje tiene mayor peso a la hora de construirlo en el audiovisual que el recurso a las fuentes. Dicho recurso a la tradición se hace más evidente si se tiene en cuenta que las películas aquí analizadas se insertan en la amplia categoría de cine histórico. Es en este tipo de cine en donde más frecuentemente, a lo largo de la historia del medio, se ha recurrido a obras pictóricas como referentes, tanto para otorgar un sentido de fidelidad a las escenas -fidelidad respecto a la imagen que el público tiene de determinada época- así como por el valor artístico de reproducir dichas imágenes previas para dotar a las creaciones cinematográficas de estatus artístico.

La detección de los modos en que ha sido construida la mujer de Magdala se ha realizado gracias al recurso de la tradición cultural convencionalizada que posibilita la detección de las continuidades y variaciones producidas en el personaje objeto de estudio. De esta forma, la conjugación de las imágenes con las fuentes, elemento clave en el proceder iconográfico, ha resultado de fundamental importancia dando como resultado la posibilidad de afirmar que son los recursos visuales de la tradición del personaje, y no los literarios, los que dan lugar a la primeras Magdalenas del celuloide. Ese mismo uso de las fuentes es el

\footnotetext{
${ }^{37}$ Aproximadamente un tercio de los capítulos que conforman la película de Zecca cuenta con algún trucaje, especialmente el truco por sustitución: capítulos $1^{\circ}, 3^{\circ}, 5^{\circ}, 10^{\circ}, 15^{\circ}, 16^{\circ}, 18^{\circ}, 30^{\circ}, 33^{\circ}, 34^{\circ}$.

38 BLACHE, Alice, 1914, p. 195.

39 BENET FERRANDO, Vicente J., 2004, p. 44.
} 
que ha hecho también posible concluir que es la Magdalena mítica, y no la evangélica, la que sigue siendo construida en el terreno audiovisual, perpetuándose así la caracterización del personaje como pecadora. Del mismo modo, quedan demostradas las posibilidades de esta rama metodológica de la Historia del Arte -iconografía e iconología- para el estudio del audiovisual con una perspectiva cultural que incluye también cuestiones de género.

En definitiva, y de manera concreta para el personaje objeto de estudio, la aparición de María Magdalena en el nuevo medio no implica una nueva visión de su figura, sino que se continúa la línea iniciada en la patrística y codificada a lo largo del tiempo en la tradición cultural. Inicialmente en el anonimato como sucede en la película de los Lumière, es en los films de Zecca y Guy donde es presentada como la pecadora en el momento de la unción. No obstante, este personaje tendrá que esperar a la década siguiente, cuando el modelo narrativo se imponga al mostrativo, para que su vida de cortesana sea objeto de atención en los metrajes dedicados a la vida de Jesús.

\section{Bibliografía}

ABEL, Richard. The Ciné Goes to Town: French Cinema, 1846-1914, Berkeley: University of California Press, 1998.

$A B E L$, Richard. "Booming the Film Business: The Historical Specificity of Early French Cinema". En: ABEL, Richard (ed.). Silent Film, Londres: Atholone Press, 1996, pp. 109-124.

BENET FERRANDO, Vicente J. La cultura del cine. Introducción a la historia y estética del cine, Barcelona, Paidós, 2004.

BLACHE, Alice. "Woman's Place in Photoplay Production", The Moving Picture World, julio 1914, p. 195, en línea <https://archive.org/stream/movingpicturewor21newy\#page/194/mode/2up > (fecha de consulta 11-03-2018).

BOILLAT, Alain; ROBERT, Valentine. "Vie et Passion de Jésus Christ (Pathé, 1902-1905): hétérogénéité des 'tableaux', déclinaison des motifs", 1895, n 60, 2010, pp. 32-55, en línea <http://1895.revues.org/3864> (Fecha de consulta 6-03-2018).

BUCHANAN, Judith. "Gospel narratives on silent film". En CARTMELL, Deborah; WHELEHAN, Imelda (eds.). The Cambridge Companion to Literature on Screen, Cambridge: Cambridge University Press, 2007, pp. 47-60.

COSANDEY, Roland; GAUDREAULT, André; GUNNING, Tom (eds.). Une invention du diable? Cinéma des premiers temps et religión/An invention of the Devil? Religion and Early Cinema, Sainte-Foy: Les Presses de I'Université Laval, Lausana: Éditions Payot, 1992.

CUÉLLAR ALEJANDRO, Carlos A. Vocabulario básico del audiovisual, Valencia: Ediciones de la Filmoteca, 2004.

ELSAESSER, Thomas. "La notion de genre et le film comme produit 'semi-fini': I'exemple de Weihnachtsglocken de Franz Hofer (1914)", 1895, n 50, 2006, pp. 6786 .
FOSTER, Gwendolyn Audrey. "Alice Guy's La Vie du Christ: A Feminist Vision of the Christ Tale", Film International, 3 septiembre 2013, en línea <http://filmint.nu/?p=9219> (fecha de consulta 11-04-2018).

GARCÍA MAHÍQUES, Rafael. Iconografía e Iconología. Volumen 2. Cuestiones de método, Madrid: Encuentro, 2009.

GAUDREAULT, André. "Del 'cine-primitivo' a la 'cinematografía-atracción'", Secuencias: Revista de historia del cine, $\mathrm{n}^{\circ}$ 26, 2007, pp. 10-28 (Traducción de "From 'Primitive cinema' to 'Kine-Attractography'" en STAVREN, Wanda (dir.). The Cinema of Attractions Reloaded, Amsterdam: Amsterdam University Press, 2006, pp. 85-104).

GRACE, Pamela. The Religious Film. Christianity and the Hagiopic, West Sussex: Wiley-Blackwell, 2009.

GUNNING, Tom. "The Cinema of Attraction: Early Film, Its Spectator and the Avant-Garde", Wide Angle, vol. 8, n 3-4, 1986, pp. 63-70.

GUNNING, Tom. "'Now you see it, now you don't'. The temporality of the cinema of attractions". En: GRIEVESON, Lee; KRÄMER, Peter (eds.). The Silent Cinema Reader, Londres-Nueva York: Routledge, 2004, pp. 41-50.

HASKINS, Susan. María Magdalena. Mito y metáfora, Barcelona: Herder, 1996.

LEFÈVRE D'ÉTAPLES, Jacques. De tribus et unica Magdalena. Disceptatio secunda, París: Ex officine Henrici Stephani, 1519.

MCMAHAN, Alison. Alice Guy Blaché. Lost Visionary of the Cinema, Nueva York-Londres: Continuum, 2002.

MOLINA-SILES, Pedro; PIQUER-CASES, Juan C.; CORTINA MARUENDA, Francisco J. "El color en los comienzos del cine. De la aplicación manual al Technicolor", En: Comité Español del Color; Sociedad Española de Óptica, Libro de Actas del X Congreso Nacional del Color, Universidad Politécnica de Valencia: Valencia, 2013, pp. 528-536, en línea <https://riunet.upv.es/bitstream/handle/10251/30118/61. pdf?sequence $=1$ \&is Allowed $=y>$ (fecha consulta 12-02-2018).

MONZÓN PERTEJO, Elena. "La evolución de la imagen conceptual de María Magdalena". En: ZAFRA MOLINA, Rafael; AZANZA LÓPEZ, José Javier (coord.). Emblemática trascendente: hermenéutica de la imagen, iconología del texto, Pamplona: Universidad de $\mathrm{Na}$ varra, 2011, pp. 529-540.

MONZÓN PERTEJO, Elena. "Iconología y cine. Construcción fílmica de María Magdalena en la película Rey de reyes de Cecil B. DeMille", Imago. Revista de Emblemática y Cultura Visual, n 4, 2012, pp. 63-78.

MONZÓN PERTEJO, Elena. María Magdalena. Continuidad y variación en la cultura audiovisual (1897-2014), Tesis doctoral en línea <http://roderic.uv.es/handle/ 10550/59155> (fecha consulta 23-06-2018).

MYCOFF, David (trad.). The Life of Saint Mary Magdalene and of her Sister Saint Martha. A Medieval Biography, Kalamazoo: Cistercian Publications, 1989.

READ, Paul. "Unnatural Colours. An Introduction to Colouring Techniques in Silent Era Movies", Film History, vol. 21, $\mathrm{n}^{\circ}$ 1, 2009, pp. 9-46.

REDI, Riccardo. "La Passion Pathé, de Ferdinand Zecca, problème de datation". En: GUIBBERT, Pierre (dir.). Les premiers ans du cinéma français, Perpiñán: Institut Jean Vigo, 1985, pp. 167-171.

ROBERT, Valentine. "Cinema and the Work of Doré". En: KAENEL, Philippe (ed.), Doré (1832-1883) Master of Imagination, París: Flammarion, 2014, pp. 287-295.

ROBERT, Valentine. "Le tableau vivant ou l'origine de I'art cinématographique". En: RAMOS, Julie (dir.), Le 
tableau vivant ou l'image performée, París: Mare \& Martin Editions, 2014, pp. 263-281.

ROBERT, Valentine. "Les tableaux animés de la production Pathé", Cine\&CIE. International Film Studies Journal, vol. XIII, n² 21, otoño 2013, pp. 15-24.

SAXL, Fritz. La vida de las imágenes. Estudios iconográficos sobre el arte occidental, Madrid: Alianza, 1989.

SHEPHERD, David J. The Bible on Silent Film. Spectacle, Story and Scripture in the Early Cinema, Cambridge: Cambridge University Press, 2013.

SLIDE, Anthony (ed.). The Memoirs of Alice Guy Blaché, Lanham, Scarecrow Press, 1996.

TATUM, W. Barnes. Jesus at the Movies. A Guide to the First Hundred Years and Beyond, Santa Clara: Polebridge Press, 2013.

VORÁGINE, Santiago. La leyenda dorada 1, Madrid: Alianza, 2001.

WARBURG, Aby. El renacimiento del paganismo. Aportaciones a la historia cultural del Renacimiento europeo, Madrid: Alianza, 2005.

\section{Filmografía}

ANDRÉANI, Henri (dir.). Le Judgement de Salomon, Francia, 1912
DAVIS, Garth (dir.). María Magdalena, Estados Unidos Reino Unido - Canadá, 2018.

GAVAULT, Paul y BERR, Georges (dir.). Joseph vendu par ses frères, Francia, 1909.

GUY, Alice (dir.). La Vida de Cristo, Francia, 1906.

HATOT, George (dir.). La Vida y Pasión de Jesucristo, Francia, 1898.

KLAW, Marc y ERLANGER, Abraham (dir.). The Horitz Passion Play, Estados Unidos, 1897.

LÉAR (dir.). La pasión de Cristo, Francia, 1897.

LUBIN, Siegmund (dir.). Passion Play, Estados Unidos, 1898.

NONGUET, Lucien (dir.). La Vie de Moïse, Francia, 1905.

OLCOTT, Sidney (dir.). Ben-Hur, Estados Unidos, 1907.

SCORSESE, Martin (dir.). La última tentación de Cristo, Estados Unidos - Canadá, 1988.

TOPI, Luigi y CRISTOFARI, Ezio (dir.). La Passione di Cristo, Italia, 1900.

VINCENT, Henry C. (dir.). The Passion Play of Oberammergau, Estados Unidos, 1898.

ZECCA, Ferdinand (dir.). La Vida y Pasión de Nuestro Señor Jesucristo, Francia, 1902-1907.

ZECCA, Ferdinand (dir.). Samsom et Dalila, Francia, 1902. 